\title{
К ВОПРОСУ ОБ ОЦЕНКЕ ОБЩЕГО СИНЕРГЕТИЧЕСКОГО ЭФФЕКТА КААСТЕРА
}

Аннотадия. $B$ статье рассматриваются подходы к расчету синергетического эффекта кластера. Для этого проведен анализ отечественных источников, выявлены наиболее распространенные методы оценки синергетического эффекта кластера. К таким методам в первую очередь следует отнести метод расчета через изменение капитала, метод расчета через снижение затрат, метод расчета на основе экспертных оценок и метод дисконтированных денежных потоков. Одной из слабых сторон выявленных методов является рассмотрение эффекта только от производственной деятельности, тогда как функиионирование кластера объединяет множество разнообразных участников, интересы и возможности которых анализируются в работе. Так, обслуживающие организации заинтересованы в работе с маситабными проектами, инновационные - во внедрении разработок и спросе на их продукиию, научно-исследовательские - наличии заказа и применимости результатов исследований, образовательные - трудоустройстве кадров и актуальности компетенций и т. д. Таким образом, вступление в кластер непроизводственных участников связано с меркантильными интересами сторон, которые не противоречат общей ицели кластера. Поэтому, реализуя внутри кластера свои возможности, все участники тем или иным образом влияют на его экономические показатели. Образовательные проекты, например, могут принести повышение прибыльности через повышение производительности труда от повышения уровня компетениий персонала. Научные проекты необходимы для модернизации оборудования, оптимизации организаилионных методов работы и m. п. Результаты проведенного исследования могут быть использованы при реализации кластерной политики в регионах, расчета эффективности кластеров и аргументации ее значения, в том числе для участников кластеров. В ходе исследования делается вывод о том, что непроизводственные участники кластера несут дополнительные эффекты, влияющиие на итоговую прибыль. Поэтому данные эффекты должны сочетаться с эффектом от синергии производственной илепочки для расчета общего синергетического эффекта кластера.

Ключевые слова: кластер, проект, синергетический эффект.

KUSHNIKOV EVGENY IGOREVICH

Ph. D. in Economics, associate Professor At the Institute of digital economy Of the "Ugra state University", e-mail: eugene-kushnikov@yandex.ru

\section{ON THE ISSUE OF ASSESSING THE OVERALL SYNERGETIC EFFECT OF THE CLUSTER}

Abstract. The article discusses approaches to the calculation of the synergistic effect of the cluster. For this purpose, the analysis of domestic sources was conducted, and the most common methods for evaluating the cluster's synergetic effect were identified. These methods include primarily the method of calculating through changes in capital, the method of calculating through cost reduction, the method of calculating based on expert estimates and the method of discounted cash flows. One of the weaknesses of the identified methods is the consideration of the effect only from production activities, while the functioning of the cluster unites a variety of different participants, whose interests and capabilities are analyzed in the work. So, service organizations are interested in working with large-scale projects, innovation in the implementation of development and the demand for their products, research the availability of ordering and applicability of research results, educational - employment of staff and the relevance of competencies, etc. Thus,

${ }^{1}$ Исследование выполнено при финансовой поддержке РФФИ в рамках научного проекта № 18-410-860008 p_a. 
joining the cluster of non-production participants is associated with the Mercantile interests of the parties, which do not contradict the overall goal of the cluster. Therefore, by implementing their capabilities within the cluster, all participants influence its economic indicators in one way or another. Educational projects, for example, can bring increased profitability through increased productivity from improving the level of staff competencies. Scientific projects are necessary for upgrading equipment, optimizing organizational methods of work, and so on. The results of the research can be used in implementing cluster policy in the regions, calculating the effectiveness of clusters and arguing its value, including for cluster participants. The study concludes that nonproductive cluster participants have additional effects that affect the final profit. Therefore, these effects must be combined with the effect of production chain synergy to calculate the overall cluster synergy effect.

Keywords: cluster, project, synergetic effect.

Введение. Реализация кластерной политики в Российской Федерации не теряет своей актуальности. Кластерная инициатива, заимствованная из международного опыта (где в достаточной степени зарекомендовала себя), по большей степени реализуется «сверху-вниз», когда кластеры создаются в том числе и по указанию органов власти. При этом приоритеты государственной поддержки и задачи развития кластеров дифференцировались в зависимости от времени и актуального типа кластеров, поставленных на повестку. Между тем большой проблемой для чиновников, как, впрочем, и для предпринимателей, является оценка результатов кластеризации, особенно если говорить о ее прогнозных значениях.

Методы исследования. Развитой группой элементов инфраструктурной поддержки является производственно-технологическая инфраструктура, которая призвана обеспечивать, создавать условия осуществления производственных процессов и являться базой для формирования инновационных систем на местах, так как осуществляет связь между наукой, бизнесом и властью, а также непосредственно влияет на внедрение технологий в производство, в том числе с непосредственным выходом на экономическое развитие территории [18].

Кластеризация также связана с оптимизацией производственных процессов и инициируется органами власти для улучшения экономики (региона, страны). Но чтобы понять, насколько эффективны процессы кластеризации, нужно рассчитать их эффективность. По мнению ряда экспертов, например Е. С. Куценко [7], отсутствие положительного эффекта или упадок при формировании цепочек, может быть связан в том числе и со слабой результативностью деятельности участников кластера. Но для объективной оценки такой характеристики необходимы расчеты. Чаще всего в этом случае используется так называемый синергетический эффект.

Под синергетическим эффектом в таком случае понимают возрастание эффективности деятельности в результате соединения, интеграции, слияния отдельных частей в единую систему за счет так называемого системного эффекта (эмерджентности) [14]. Что, по сути, не противоречит понятию синергии (от др.-греч. «вместе» + «дело, труд, работа, (воз)действие»), которую, например, в экономико-математическом словаре определяют как экономию и другие выгоды, получаемые в результате объединения двух или большего числа компаний, благодаря более полному использованию имеющихся у них возможностей (опыта и квалификации работников, каналов сбыта продукции др.). Уже эти определения подталкивают к вопросу оценки эффективности объединения участников кластера.

Возможности достижения эффекта синергизма анализируются достаточно давно, в том числе и не экономистами, а математиками, физиками, биологами, лингвистами. Несмотря на исторический оттенок исследуемой тематики, проблемы получения эффекта синергии и его оценки остаются актуальными и сегодня. Это связано с поиском драйверов экономического и промышленного развития, что и привело к кластеризации как возможности привлечения дополнительных инвестиций в бизнес и улучшения инвестиционного климата регионов в целом; возможности повышения занятости населения и повышения уровня их жизни; возможности обеспечения устойчивого развития региональной экономики и эффективности предприятий участников кластеров.

В экономической науке принято считать, что основные постулаты относительно эффективности синергии сформулировали М. Портер [11] и И. Ансофф [4]. Но и современные ученые 
активно исследуют данное направление, предлагая свои решения или усовершенствуя предложенные ранее. Так в статье М. Э. Буяновой и Л. В. Дмитриевой [5] описана комплексная методика количественной оценки синергетического эффекта, основанная на экономии ресурсов за счет кооперации и совместного использования (от снижения трансакционных издержек, стоимости капитала, маркетинговых издержек, диффузии инноваций и совместного использования инфраструктуры).

Ф. В. Шутилов [17] предлагает оценивать синергетический эффект через авторские показатели, такие как, например, «показатель взаимодействия», но здесь не удалось избежать субъективизма, так как общий эффект, по сути, выходит из метода экспертных оценок. Последний очень часто применим в исследованиях по оценке эффективности кластеров как метод экспресс-анализа, а для снижения степени субъективности обычно дополняется балльной системой оценок и весовыми коэффициентами, как, например, в работе С. Г. Авдониной [2].

В. С. Просалова и Е.Н. Смольянинова [13] с учетом трудов ученых прошлых лет предложили авторскую формулу, расчет по которой в том числе показывает, что кластер начинает терять синергетический эффект на третий год своего существования, что, с одной стороны, облегчает задачу выбора горизонта планирования, с другой - сужает эффективность кластеризации в среднесрочном и долгосрочном периодах.

М. В. Акульчева и Д. К. Жимантас [3] предлагают оценивать эффект сетевых взаимодействий через отношение общей эффективности сети взаимодействия к среднему из частных показателей эффективности предприятий сети взаимодействия. Ими же при этом отмечается, что показателями синергетического эффекта могут быть не только количественные показатели, но и повышение качества продукта, процесса, работы персонала, расширение деловых связей, оптимизация внешних связей и т. п.

Таким образом, анализ существующих методик расчета синергетического эффекта кластера свидетельствует о многообразии подходов. При этом нельзя не отметить, что исследуемые методики обладают рядом системных недостатков:

- слабое обоснование используемых показателей;

- узость расчетов в отношении участников кластера (отсутствие универсальности);

- субъективность;

- оценка эффекта только от производственной деятельности;

- другое.

Выделяя из всех подходов наиболее распространенные и удачные, с точки зрения соотношения результата и отрицательных сторон можно отметить следующие:

- метод расчета через изменение капитала [15];

- метод расчета через снижение затрат [15];

- метод расчета на основе экспертных оценок [8];

- метод дисконтированных денежных потоков [6].

Оценка кластерного эффекта через изменение стоимости капитала построена на основе расчета его средневзвешенной стоимости. Так, ежегодный эффект от снижения стоимости капитала рассчитывается по следующей формуле:

$$
\exists_{\text {инв }}=K * \Delta W A C C
$$

где $K$ - размер совокупного капитала компании; WACC - средневзвешенная стоимость капитала.

Формула и расчёт средневзвешенной стоимости капитала подробно раскрываются в работе [19] и связаны с поиском средней процентной ставки, которая учитывает ставки по всем видам капитала (собственный, заемный).

Второй метод связан с расчетом экономии на издержках. Например, при кластеризации компании входящие в кластер могут использовать единый бренд, акцентировать усилия маркетинговых служб лишь на продаже последнего в производственной цепочке продукта, что позволит значительно снизить затраты на рекламу. Формула для расчета эффекта за счет сокращения издержек на маркетинг следующая: 


$$
\exists_{\text {мар }}=\Delta \exists_{\text {изд }}+\Delta \mathrm{B}
$$

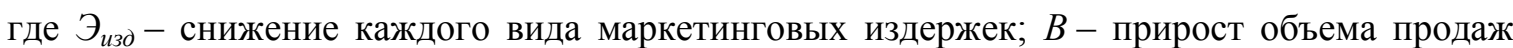
компаний кластера за счет продвижения бренда кластера.

По аналогии можно рассчитать экономию и от объединения и других статей расходов, а также их совокупности.

Третьим распространенным подходом оценки эффекта синергии является метод экспертных оценок. Более подробно этот пример можно рассмотреть по работе Н. И. Клепиковой [15], которая учитывает пять принципиальных характеристик кластеров, утвержденных Методическими рекомендациями по реализации кластерной политики [9]:

1. Наличие конкурентоспособных предприятий.

2. Наличие у региона/территории конкурентных преимуществ для развития кластера.

3. Географическая концентрация и близость.

4. Широкий набор участников и наличие «критической массы».

5. Наличие связей и взаимодействия между участниками кластеров.

Экспертная группа должна оценить каждый критерий по шкале, например пятибалльной, и умножить полученные значения на весовые коэффициенты критерия для эффективности кластера, выявленные также экспертным путем или на основе анализа (статистического или математического).

Итоговый показатель рассчитывается как сумма экспертных оценок, измененных на величину весовых коэффициентов или как среднеарифметическое. В данном случае эффект кластера рассчитывается от сравнения с другим кластером или от среднего значения (для этого выбирают нечетные шкалы). Так, при использовании, например пятибалльной шкалы и пяти критериев, среднее значение равно 12,5 балла.

Четвертый подход связан с измерением изменения прибыльности участников кластера. Самый простой вариант расчета - через оценку их суммарной чистой прибыли и амортизационных отчислений, получаемых в результате реализации инвестиционных проектов инновационного кластера. Тогда экономическая эффективность кластера в результате реализации совокупности кластерных проектов будет равна:

$$
\ni_{\mathrm{Kлn}}=\sum_{i=0}^{m} \Pi_{i}
$$

$m$ - количество инвестиционных проектов за определенное число лет функционирования кластера;

$\Pi_{i}$ - суммарная чистая прибыль и начисленная амортизация в результате реализации $i$-го инвестиционного проекта кластера;

$$
P_{m}=\sum \frac{\Pi_{j}}{1+d^{n}}
$$

где $\Pi_{j}-$ прогнозируемая величина чистой прибыли и амортизационных отчислений, генерируемая инвестиционным проектом кластера в ј-м году его реализации;

$n$ - предполагаемое число лет реализации инвестиционного проекта;

$d$ - принятая ставка дисконтирования чистой прибыли.

В соответствии с рассматриваемой методикой ставка дисконтирования должна отражать альтернативные издержки всех источников капитала, взвешенные по относительному вкладу каждого в совокупный капитал компании [1].

Резюме описанного выше наиболее наглядно можно представить в виде таблицы 1. 
КУшников Е.И.

К ВОПРОСУ ОБ ОЦЕНКЕ ОБЩЕГО СИНЕРГЕТИЧЕСКОГО ЭФФЕКТА КЛАСТЕРА

Таблица 1

\section{Положительные и отрицательные стороны основных подходов к оценке синергетического эффекта кластера}

\begin{tabular}{|l|l|l|}
\hline \multicolumn{1}{|c|}{ Метод } & \multicolumn{1}{|c|}{ Положительные стороны } & \multicolumn{1}{|c|}{ Отрицательные стороны } \\
\hline $\begin{array}{l}\text { Метод расчета увеличения предложе- } \\
\text { ния капитала и снижения его стоимо- } \\
\text { сти }\end{array}$ & $\begin{array}{l}\text { Позволяет отдельно оценить влияние } \\
\text { лизациютического эффекта на капита- } \\
\text { яния }\end{array}$ & $\begin{array}{l}\text { Оценивается лишь потенциальный } \\
\text { эффект }\end{array}$ \\
\hline $\begin{array}{l}\text { Метод расчета затрат на маркетинго- } \\
\text { вые исследования }\end{array}$ & $\begin{array}{l}\text { Отсутствие вероятностных характе- } \\
\text { ристик }\end{array}$ & $\begin{array}{l}\text { Не учитываются иные сокращения } \\
\text { издерек от кластеризации }\end{array}$ \\
\hline $\begin{array}{l}\text { Метод экспертных оценок } \\
\text { Возможность учета разнообразных } \\
\text { характеристик, в том числе косвен- } \\
\text { ных, в мнении эксперта }\end{array}$ & $\begin{array}{l}\text { Субьективность, максимальное зна- } \\
\text { ной шкалой }\end{array}$ \\
\hline $\begin{array}{l}\text { Метота ограничено балль- } \\
\text { потоков (доходный подход) }\end{array}$ & $\begin{array}{l}\text { Заложена значительная доля неопре- } \\
\text { деленности, которая носит вероят- } \\
\text { ностный характер }\end{array}$ \\
\hline
\end{tabular}

Таким образом, проблема выбора метода для оценки синергетического эффекта кластера связана с наличием и доступностью информации, развитостью системы его управления, сбора данных, анализа процессов и т. д.

Результаты. Проведенный анализ методов оценки синергетического эффекта показал наличие достаточного количества подходов. Со своей стороны необходимо обратить внимание на то, что, несмотря на производственную направленность большинства кластерных образований в экономике, требуется учет эффективности всех участников кластеров, в том числе и из непроизводственной сферы.

Так, выявление и дробление участников, непосредственно связанных с деятельностью кластера, на более узкие группы позволяет конкретизировать и их интересы (таблица 2).

Таблица 2

\section{Изменение экономических показателей кластера до и после реализации совместного проекта}

\begin{tabular}{|l|l|l|}
\hline \multicolumn{1}{|c|}{ Наименование участника } & \multicolumn{1}{|c|}{ Интерес } & \multicolumn{1}{|c|}{ Возможности } \\
\hline Производители & Повышение прибыльности бизнеса & $\begin{array}{l}\text { Стабильные поставки для соседей по } \\
\text { произвдстенной цепочке }\end{array}$ \\
\hline Поставщики & $\begin{array}{l}\text { Оптовые поставки, долговременный } \\
\text { спрос }\end{array}$ & Система скидок, план поставок \\
\hline Обслуживающие & $\begin{array}{l}\text { Обслуживание крупного производ- } \\
\text { ственного комплекса }\end{array}$ & Аутсорсинг, комплексный подход \\
\hline Инновационные & Внедрение разработок, продажа & $\begin{array}{l}\text { Технологические инвестиции, допро- } \\
\text { дажная апробация, обкатка за свой } \\
\text { счет }\end{array}$ \\
\hline Научно-исследовательские & $\begin{array}{l}\text { Практико-ориентированные исследо- } \\
\text { вания, 100 \% возмещение затрат от } \\
\text { государства [12] }\end{array}$ & $\begin{array}{l}\text { Индивидуальный подход, потенциал } \\
\text { ние ОИС, научное сопровожде- }\end{array}$ \\
\hline Образовательные & $\begin{array}{l}\text { наказ на кадры, трудоустройство } \\
\text { кадров, актуальность компетенций }\end{array}$ & $\begin{array}{l}\text { Персонифицированная подготовка, } \\
\text { базовая кафедра, повышение квали- } \\
\text { фикации, адаптивные программы }\end{array}$ \\
\hline Инвестиционные & $\begin{array}{l}\text { Получение высокодоходных возвра- } \\
\text { тов инвестиций }\end{array}$ & $\begin{array}{l}\text { Инвестиции в разных форматах, объ- } \\
\text { емах, сроках }\end{array}$ \\
\hline Инновационная инфраструктура & Востребованность услуг & $\begin{array}{l}\text { Бесплатные госуслуги, субсидирова- } \\
\text { ние затрат, аутсорсинг }\end{array}$ \\
\hline Рыночная инфраструктра & Востребованность услуг & $\begin{array}{l}\text { Бесплатные госуслуги, субсидирова- } \\
\text { ние затрат, аутсорсинг }\end{array}$ \\
\hline
\end{tabular}


Таким образом, каждый из участников кластера может выступать инвестором, так как обладает разнородным инвестиционным ресурсом (X на рисунке 1). Специфика деятельности участников различна, что не позволяет им напрямую участвовать в основном проекте кластера - производственной деятельности. Но даже на нее влияет множество факторов, укрепление которых возможно путем реализации вспомогательных проектов. В качестве таких проектов могут быть представлены:

- инфраструктурные проекты, которые призваны повысить эффективность инфраструктурной поддержки или расширить ее функционал;

- инновационные проекты, связанные с апробацией, тестированием и внедрением результатов инновационной деятельности малых инновационных компаний;

- образовательные проекты, которые направлены на улучшение качества образования, актуализацию его под запросы участников кластера, повышение в нем практической составляющей;

- научные проекты, призванные привнести не только новые производственные технологии, но и методы организации производства и оптимизации производственных процессов;

- смешанные проекты, объединяющие различных участников проектов с целью повышения общей эффективности деятельности кластера (по-другому - кластерные проекты).

В целом при широком разнообразии возможных проектов, которые могут быть реализованы участниками кластеров (рисунок 1), важно понимать, что все они, по сути, направлены на достижение эффекта $(\mathrm{E})$ через повышение прибыльности $(\Delta \mathrm{Z})$. Это может быть достигнуто, например, через создание и генерации новых знаний, их формализацию и распределение внутри предприятия и кластера с выходом на формирование конкурентного преимущества [16] или проще - через повышение уровня компетенций персонала и рост производительности труда (для образовательных проектов); через создание технологических инноваций, оптимизацию организационных методов работы (для научных проектов) [10]; через сокращение времени выхода продукта на рынок, повышение уровня сервисных услуг (для инфраструктурных проектов) [20] и т. д.

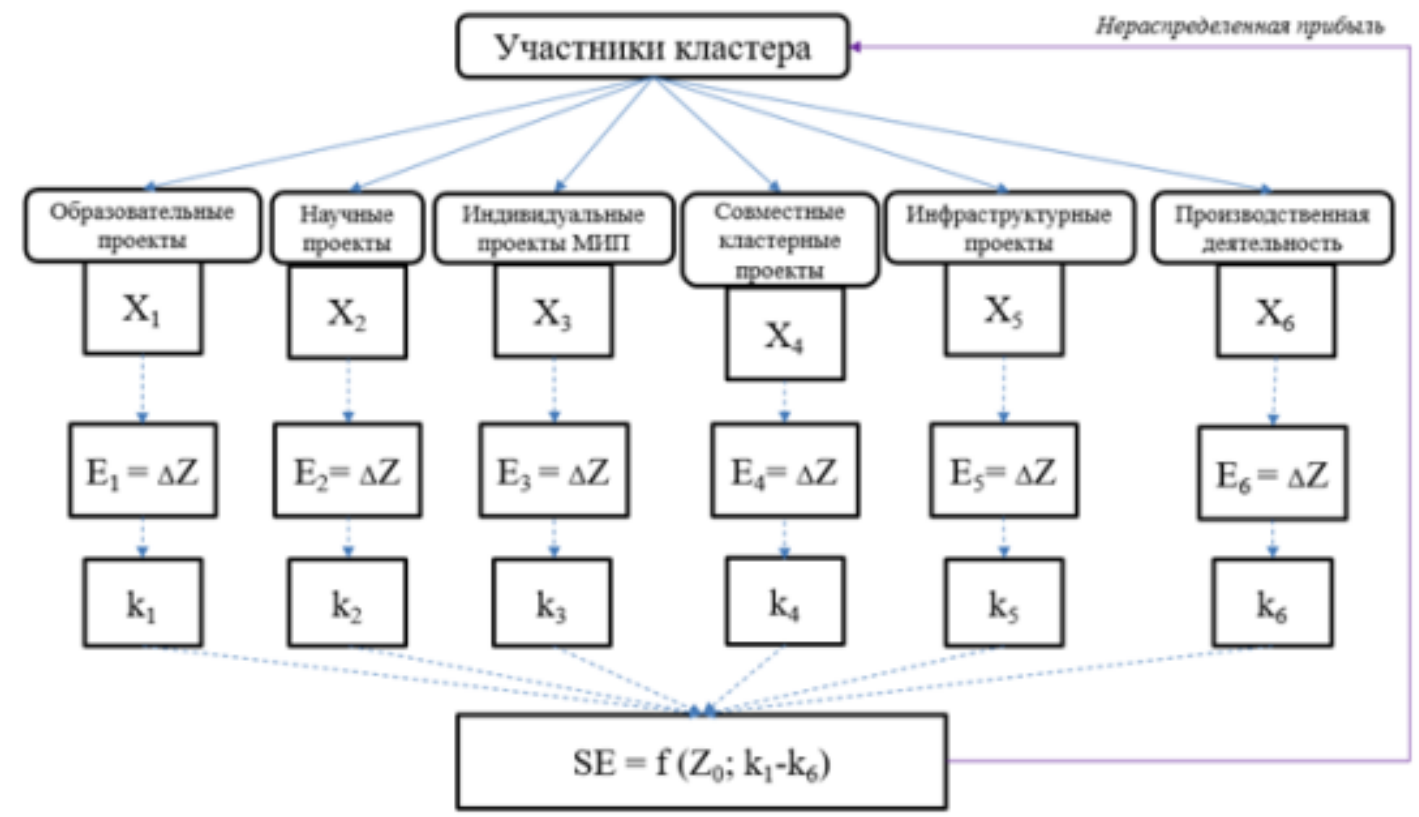

Pис. 1. Многообразие кластерных проектов в формировании общего синергетического эффекта для кластера.

Для расчета общего синергетического эффекта кластера (SE) нужно использовать сумму эффектов по каждому проекту. Для приведения к однообразию данные эффекты потребуется преобразовать в коэффициенты, способные продемонстрировать как совокупность эффектов от реализации проектов может сказаться на общем эффекте для всего кластера. 
Выводы. На основе использования обоснованных методов оценки эффективности кластерного подхода к социально-экономическому развитию регионов Российской Федерации, представленных в аналитической части работы, и с учетом многообразия, реализуемого участниками кластера проектов, оценка общего синергетического эффекта должна учитывать увеличение суммарной прибыльности участников кластера, в том числе за счет многообразия разнородных инвестиционных вливаний.

Литература

1. Авдонина С. Г. Количественные методы оценки синергетического эффекта инновачионного кластера // Официальный сайт Казанского федерального университета. [Электронньй ресурс]. Режим доcmyna: http://kpfu.ru/docs/F 1221512295/4_kolmet_avd.pdf, свободный. - Загл. с экрана.

2. Авдонина С. Г. Синергетический эффект кластерных образований и параметры его оиенки // Региональная экономика и управление: электронный научный журнал. - 2012. - № 1 (29). [Электронный ресурс]. Режим доступа: https://eеe-region.ru/article/2904/, свободный. - Загл. с экрана.

3. Акульчева М. В., Жимантас Д. К. Методика формирования сетевого взаимодействия предприятий 6 территориальном кластере // Организатор производства. - 2018. - T.26 - № 2. - С. 62-73.

4. Ансофф И. Новая корпоративная стратегия. СПб.: Питер, 1999. - 416 с.

5. Буянова М. Э., Дмитриева Л. В. Оченка эффективности создания региональных инновационных кластеров // Вестник Волгоградского государственного университета. - 2012. - № 2 (21). - C. 54-62.

6. Клепикова Н. И. Оценка эффективности создания отраслевого кластера // Фундаментальные исследования. - 2013. - № 4 (часть 4). - C. 934-939.

7. Куценко Е. С. Рациональная кластерная стратегия: маневрируя между провалами рынка и государства // Форсайт. - 2017. - № 3. [Электронный ресурс]. Режим достуnа: https://cyberleninka.ru/article/n/ ratsionalnaya-klasternaya-strategiya-manevriruya-mezhdu-provalami-rynka-i-gosudarstva (дата обращения: 22.11.2019), свободный. - Загл. с экрана.

8. Латышев А. Ю. Особенности формирования российских монополий в разрезе региональных и отраслевых кластеров в краткосрочном и долгосрочном периоде // Новый университет. - 2013. - № 12 (34). C. $62-64$

9. Методические рекомендации по реализациии кластерной политики в субъектах Российской Федерации (подписаны заместителем Министра экономического развития Российской Федерации А. Н. Кле-

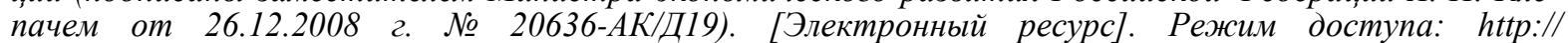
economy.gov.ru/minec/activity/sections/innovations/development/doc1248781537747, свободный. - Загл. с экрана.

10. Пелихов Н. В., Целикова О. Г., Кушников Е. И., Родионова А. В. Образование и наука как один из важнейших ресурсов обеспечения экономического роста и инновационного развития регионов // Региональная экономика: теория и практика. - 2008. - № 33. - С. 25-33.

11. Портер М. Конкурениия. - М.: И. Д. Вильямс, 2005. - 608 с.

12. Постановление Правительства Российской Федерации от 28.01.2016 № 41 «Об утверждении Правил предоставления из федерального бюджета субсидий участникам промышленных кластеров на возмещение части затрат при реализации совместных проектов по производству промышленной продукиии кластера в целях импортозамещения».

13. Просалова В. С., Смольянинова Е. Н. Анализ подходов оченки синергетического эффекта кластера как результата управления инновациями в долгосрочной перспективе. // Азимут научных исследований: экономика и управление. - 2017. [Электронный ресурс]. Режим доступа: https://cyberleninka.ru/article/ n/analiz-podhodov-otsenki-sinergeticheskogo-effekta-klastera-kak-rezultata-upravleniya-innovatsiyami-v-

dolgosrochnoy-perspektive (дата обращения: 22.11.2019), свободный. - Загл. с экрана.

14. Райзберг Б. А. Современный экономический словарь / Б. А. Райзберг, Л. Ш. Лозовский, Е. Б. Стародубиева. - 6-е изд., перераб. и доп. - Москва : ИНФРА-М,2019. - 512 с.

15. Ридченко А. И. Прочессы оптимизащии образования региональных инновационных кластеров // Наука о человеке: гуманитарные исследования. - 2013. - № 1(11). - С. 76-82.

16. Хасанов Р. Х. Синергетический эффект кластера // Проблемы современной экономики. - 2009. - № 3 (31). [Электронный ресурс]. Режим достуnа: http://www.m-economy.ru/art.php?nArtId=2784 (дата обращения: 22.11.2019), свободный. - Загл. с экрана.

17. Шутилов Ф. В. Методы оиенки эффективности и синергетический эффект кластеров // Научный вестник ЮИМ. - 2013. - № 2. - С. 81-85.

18. Casadella V., Uzunidis D. National Innovation Systems of the South, Innovation and Economic Development Policies: A Multidimensional Approach. Journal of Innovation Economics \& Management, 23. P. 137157. doi: 10.3917/jie.pr1.0007.

19. Farber A., Gillet R.L., Szafarz A. General Formula for the Wacc // International Journal of Business. Vol. 11. No. 2. 2006. [An electronic resource]. Access mode: https://ssrn.com/abstract $=898420$, free. Heading from the screen.

20. Rohracher H., Truffer B., Markard J. Doing Institutional Analysis of Innovation Systems (a conceptual framework). [An electronic resource]. Access mode: https://www.dime-eu.org/files/active/0/ Truffer_Institutional\%20 Analysis_Aug 08.pdf(Date of access: 24.05.2019), free. Heading from the screen.

\section{References:}

1. Avdonina S. G. Kolichestvennye metody ocenki sinergeticheskogo effekta innovacionnogo klastera // Ofi- 
cial'nyj sajt Kazanskogo federal'nogo universiteta. [Elektronnyj resurs]. Rezhim dostupa: http://kpfu.ru/docs/F 1221512295/4 kolmet avd.pdf, svobodnyj. - Zagl. s ekrana.

2. Avdonina S. G. Sinergeticheskij effekt klasternyh obrazovanij i parametry ego ocenki // Regional'naya ekonomika i upravlenie: elektronnyj nauchnyj zhurnal. - 2012. - № 1 (29). [Elektronnyj resurs]. Rezhim dostupa: https://eee-region.ru/article/2904/, svobodnyj. - Zagl. s ekrana.

3. Akul'cheva M. V., ZHimantas D. K. Metodika formirovaniya setevogo vzaimodejstviya predpriyatij $v$ territorial'nom klastere // Organizator proizvodstva. - 2018. - T.26 - № 2. - S. 62-73.

4. Ansoff I. Novaya korporativnaya strategiya. SPb.: Piter, 1999. - 416 s.

5. Buyanova M. E., Dmitrieva L. V. Ocenka effektivnosti sozdaniya regional'nyh innovacionnyh klasterov // Vestnik Volgogradskogo gosudarstvennogo universiteta. - 2012. - № 2 (21). - S. 54-62.

6. Klepikova N. I. Ocenka effektivnosti sozdaniya otraslevogo klastera // Fundamental'nye issledovaniya. 2013. - № 4 (chast' 4). - S. 934-939.

7. Kucenko E. C. Racional'naya klasternaya strategiya: manevriruya mezhdu provalami rynka i gosudarstva // Forsajt. - 2017. - № 3. [Elektronnyj resurs]. Rezhim dostupa: https://cyberleninka.ru/article/n/ratsionalnayaklasternaya-strategiya-manevriruya-mezhdu-provalami-rynka-i-gosudarstva (data obrashcheniya: 22.11.2019), svobodnyj. - Zagl. s ekrana.

8. Latyshev A. YU. Osobennosti formirovaniya rossijskih monopolij v razreze regional'nyh i otraslevyh klasterov v kratkosrochnom i dolgosrochnom periode // Novyj universitet. - 2013. - № 12 (34). - S. 62-64

9. Metodicheskie rekomendacii po realizacii klasternoj politiki v subëktah Rossijskoj Federacii (podpisany zamestitelem Ministra ekonomicheskogo razvitiya Rossijskoj Federacii A. N. Klepachem ot 26.12.2008 g. № 20636-AK/D19). [Elektronnyj resurs]. Rezhim dostupa: http://economy.gov.ru/minec/activity/sections/ innovations/development/doc1248781537747, svobodnyj. - Zagl. s ekrana.

10. Pelihov N. V., Celikova O. G., Kushnikov E. I., Rodionova A. V. Obrazovanie i nauka kak odin iz vazhnejshih resursov obespecheniya ekonomicheskogo rosta i innovacionnogo razvitiya regionov // Regional'naya ekonomika: teoriya i praktika. - 2008. - № 33. - S. 25-33.

11. Porter M. Konkurenciya. - M.: I. D. Vil'yams, 2005. - 608 s.

12. Postanovlenie Pravitel'stva Rossijskoj Federacii ot 28.01.2016 № 41 «Ob utverzhdenii Pravil predostavleniya iz federal'nogo byudzheta subsidij uchastnikam promyshlennyh klasterov na vozmeshchenie chasti zatrat pri realizacii sovmestnyh proektov po proizvodstvu promyshlennoj produkcii klastera $v$ celyah importozameshcheniya».

13. Prosalova V. S., Smol'yaninova E. N. Analiz podhodov ocenki sinergeticheskogo effekta klastera kak rezul'tata upravleniya innovaciyami $v$ dolgosrochnoj perspektive. // Azimut nauchnyh issledovanij: ekonomika $i$ upravlenie. - 2017. [Elektronnyj resurs]. Rezhim dostupa: https://cyberleninka.ru/article/n/analiz-podhodovotsenki-sinergeticheskogo-effekta-klastera-kak-rezultata-upravleniya-innovatsiyami-v-dolgosrochnoyperspektive (data obrashcheniya: 22.11.2019), svobodnyj. - Zagl. s ekrana.

14. Rajzberg B. A. Sovremennyj ekonomicheskij slovar' / B. A. Rajzberg, L. SH. Lozovskij, E. B. Starodubceva. - 6-e izd., pererab. i dop. - Moskva : INFRA-M,2019. - 512 s.

15. Ridchenko A. I. Processy optimizacii obrazovaniya regional'nyh innovacionnyh klasterov // Nauka o cheloveke: gumanitarnye issledovaniya. - 2013. - № 1(11). - S. 76-82.

16. Hasanov R. H. Sinergeticheskij effekt klastera // Problemy sovremennoj ekonomiki. - 2009. - № 3 (31). [Elektronnyj resurs]. Rezhim dostupa: http://www.m-economy.ru/art.php?nArtId=2784 (data obrashcheniya: 22.11.2019), svobodnyj. - Zagl. s ekrana.

17. SHutilov F. V. Metody ocenki effektivnosti i sinergeticheskij effekt klasterov // Nauchnyj vestnik YUIM. 2013. - № 2. - S. 81-85.

18. Casadella V., Uzunidis D. National Innovation Systems of the South, Innovation and Economic Development Policies: A Multidimensional Approach. Journal of Innovation Economics \& Management, 23. P. $137-$ 157. doi: 10.3917/jie.pr1.0007.

19. Farber A., Gillet R.L., Szafarz A. General Formula for the Wacc // International Journal of Business. Vol. 11. No. 2. 2006. [An electronic resource]. Access mode: https://ssrn.com/abstract $=898420$, free. Heading from the screen.

20. Rohracher H., Truffer B., Markard J. Doing Institutional Analysis of Innovation Systems (a conceptual framework). [An electronic resource]. Access mode: https://www.dime-eu.org/files/active/0/ Truffer_Institutional\%20 Analysis_Aug 08.pdf(Date of access: 24.05.2019), free. Heading from the screen. 